\title{
Micro-Structure, Ac Conductivity and Spectroscopic Studies of Cupric Sulphate Doped PVA/PVP Polymer Composites
}

\author{
K. Hemalatha ${ }^{1}$, H. Somashekarappa ${ }^{1}$, R. Somashekar ${ }^{2}$ \\ ${ }^{1}$ Department of Physics, Yuvaraja's College, University of Mysore, Mysore, India \\ ${ }^{2}$ Department of Studies in Material Sciences, University of Mysore, Mysore, India \\ Email: ${ }^{\text {drhssappa@gmail.com }}$
}

Received 25 August 2015; accepted 13 October 2015; published 16 October 2015

Copyright (C 2015 by authors and Scientific Research Publishing Inc.

This work is licensed under the Creative Commons Attribution International License (CC BY). http://creativecommons.org/licenses/by/4.0/

(c) (i) Open Access

\section{Abstract}

A series of polyvinyl alcohol/polyvinyl pyrrolidone polymer composite films doped with different amount of cupric sulphate $\left(\mathrm{CuSO}_{4}\right)$ were prepared by means of solution casting technique. These films were characterized by X-ray diffraction (XRD), Fourier transform infrared spectroscopy (FT-IR), Ultraviolet-Visible absorbance spectroscopy (UV-Vis) and Ac conductivity measurement studies. XRD patterns of these films recorded at room temperature show the increase in amorphousity of the matrix with the increase in the concentration of $\mathrm{CuSO}_{4}$ in polymer composites. Microstructural parameters were computed using an in-house program employing XRD data. Recorded FT-IR spectra give information about the stretching and bending of the characteristic absorption bands in these films. The variation in the transmittance has been studied with the help of recorded UV-Vis spectra and hence the optical band gap present in the samples is also calculated. The measured Ac conductivity shows how the conductivity varies in these films with the presence of different amount of $\mathrm{CuSO}_{4}$ in these films.

\section{Keywords}

Crystallanity, X-Ray Diffraction, Amorphous, Microstructural Parameters, Ac Conductivity

\section{Introduction}

Extensive investigations on conductive polymers have been taken place in recent years in view of their important applications in electronic, electrochemical and optical devices [1] [2]. Electrical conductivity can be ob-

\footnotetext{
${ }^{*}$ Corresponding author.
}

How to cite this paper: Hemalatha, K., Somashekarappa, H. and Somashekar, R. (2015) Micro-Structure, Ac Conductivity and Spectroscopic Studies of Cupric Sulphate Doped PVA/PVP Polymer Composites. Advances in Materials Physics and Chemistry, 5, 408-418. http://dx.doi.org/10.4236/ampc.2015.510041 
tained in insulating polymer either by modifying the electronic structure of the polymer chain through doping with metallic ions or by filling the material with electrically conducting particles [3]. However, the properties of polymer composites depend upon the nature of the host polymer and different characteristics of inorganic fillers like their chemical nature, size, crystallinity, concentration and distribution in polymer matrix [4]. Different additives are usually added to polymer in order to modify and improve its properties [5]-[9].

Polyvinyl alcohol is a well-known semicrystalline, water-soluble and biodegradable polymer used in practical applications because of its easy preparation, excellent chemical resistance and physical properties [10]-[12]. It has a carbon chain backbone with hydroxyl groups attached to methane carbons. These OH-groups providing the bridging between adjacent chains lead to photoluminescence, mechanical strength and endure various dopings. Due to this property, the polymer allows homogeneous dispersion and good environmental stability to embedded metal particles [13] [14].

Polyvinyl pyrrolidone is a vinyl polymer possessing planar and highly polar side groups due to the peptide bond in the lactam ring. It deserves a special attention among the conjugated polymers because of the high environmental stability, easy processability and moderate thermal conductivity [15] [16].

When these two polymers are mixed, the interaction between PVA and PVP is expected to occur through interchain hydrogen bonding between the hydroxyl group of PVA and the carbonyl group of PVP [17]-[20].

In this work different amount of cupric sulphate is added to PVA/PVP polymer blend and the resulting films are characterized using various techniques like X-ray, FT-IR, and UV-Vis spectroscopy. The obtained results have been quantified in terms of microstructural parameters derived from XRD studies.

\section{Theory}

Normally, XRD pattern from polymers are known to consist of broadened Bragg reflection. This broadening occurs due to various factors like, i) Instrumental broadening; ii) Crystallite size, i.e. number of unit cells participating to scatter X-rays in phase; iii) Lattice strain, which is due to paracrystalline matrix of these polymers; iv) Stacking faults and others. For correcting the broadening due to instrument, we collect the XRD data from a well drilled iron and employing Stokes method. The entire XRD patterns from polymer are corrected for instrumental broadening. The intensity of a Bragg profile can be expanded in terms of Fourier coefficients and it is given by

$$
I_{h k l}(s)=\sum_{n=0}^{\infty} A_{h k l} \cos \left\{2 n \pi d_{h k l}\left(s-s_{0}\right)\right\}
$$

where,

$$
A_{h k l}(n)=A_{h k l}^{s}(n) \cdot A_{h k l}^{d}(n)
$$

$A_{h k l}^{s}(n)$ are strain coefficients [21] [22]. Fourier analysis of a Bragg reflection profile must always be performed [23] over the complete cycle of the fundamental form $d\left(s-s_{0}\right)=+\frac{1}{2}$ to $-\frac{1}{2}$, which is rarely possible experimentally. We do this analysis with the available truncated range by introducing truncated correction [24]. For a paracrystalline material, with Gaussian strain distribution $A_{h k l}(n)$ [22]-[27] turns out to be

$$
A_{h k l}^{d}(n)=\exp \left(2 \pi^{2} n^{2} m g^{2}\right) \text {. }
$$

Here $m$ is the order of the reflection and $g=\Delta d / d$ is the lattice strain. Normally one also defines mean square strain $\varepsilon^{2}$ that is given by $g^{2} / n$. This mean square strain is dependent on $n$ (or column length $L=n d$ ), whereas $g$ is not. With exponential distribution function for column length, we have,

$$
A_{h k l}^{d}(n)=A(0)\left[\frac{1-n}{N}\right] \text { if } n<p, A(0)\left[\frac{\exp [-\propto(n-p)]}{N}\right] \text { if } n \geq p .
$$

In the above equation $\propto=1 /(n-p)$ refers to the width of the distribution and $p$ is the smallest number of unit cells in a column.

The whole powder pattern of samples were simulated using individual Bragg reflection represented by the above equations using 


$$
I(s)=\sum_{h k l}\left(\omega_{h k l} I_{h k l}-B G\right)
$$

where $\omega_{h k l}$ are the appropriate weight functions for the $(h k l)$ Bragg reflections. Here $s$ takes the whole range ( $2 \theta \approx 6^{\circ}$ to $80^{\circ}$ ) of XRD recording of the sample. $B G$ is an error parameter introduced to correct the background estimations [24] [28]-[31]. Whole XRD pattern is simulated using Equations (1) to (5).

\section{Materials and Methods}

\subsection{Materials}

Polyvinyl alcohol (PVA), polyvinyl pyrrolidone (PVP) and cupric sulphate $\left(\mathrm{CuSO}_{4}\right)$ were procured from S D fine-chem. limited, Mumbai, India.

\subsection{Preparation of Cupric Sulphate Doped PVA/PVP Composite Films}

Samples were prepared using solution casting method. Stock solution PVA is prepared by dissolving $5 \mathrm{wt} \%$ of PVA in distilled water, stirred for 6 hours at room temperature using a magnetic stirrer, double filtered and allowed to settle for a day. Similarly stock solution of 3\% of PVP is also prepared in distilled water. Different concentrations of PVA/PVP solutions cast on petri dishes and allowed to dry at room temperature. After complete drying the films were peeled out of these dishes. The film with 50/50 concentration was found to be blended well hence the solution of this percentage was used to prepare the different concentrations of cupric sulphate doped PVA/PVP films. The cupric sulphate was added to the 50/50 (PVA/PVP) stock solution with different weight concentrations of $0.2 \%, 0.4 \%, 0.6 \%, 0.8 \%$ and $1.0 \%$, stirred at room temperature using magnetic stirrer for half an hour to get more homogeneous solution and then the solution was poured into petri dish placed on flat surface and allowed to dry completely at room temperature. The dried composite films were peeled out and cut in suitable sizes and were used in these studies.

\section{Experimental}

\subsection{X-Ray Diffraction (XRD) Recording}

XRD patterns of pure and $\mathrm{CuSO}_{4}$ doped PVA/PVP polymer composite films of different concentrations were recorded using Rigaku Miniflex II Desktop X-ray Diffractometer equipped with $\mathrm{CuK}_{\alpha}$ radiation (wavelength = $1.5406 \AA$ ) and a graphite monochromator. The samples were scanned in the $2 \theta$ range $6^{\circ}-80^{\circ}$ and the specifications used for the recording are $30 \mathrm{kV}$ and $15 \mathrm{~mA}$ with the scanning speed of $5 \% \mathrm{~min}$. After correcting for instrumental broadening the microstructural parameters of these polymer composites were computed by employing whole powder pattern fitting method. Analysis of X-ray data is given in theory section. Fitted XRD pattern for the samples is as shown in Figure 1.

\subsection{Recording of Ultraviolet and Visible (UV-Vis) Spectra}

The absorbance of pure and $\mathrm{CuSO}_{4}$ doped PVA/PVP polymer composites were recorded at room temperature in the UV-visible wavelength range using Labtronics MODEL LT-2800 double beam UV-Visible spectrophotometer. The recorded UV-Visible spectra of pure and $\mathrm{CuSO}_{4}$ doped PVA/PVP films is as shown in Figure 2.

\subsection{Recording of Fourier Transform Infrared (FT-IR) Spectra}

The Infrared transmission spectra of these polymer samples were recorded at room temperature in the wave number range of $4000-500 \mathrm{~cm}^{-1}$ using Perkin Elmer Spectrum. The recorded FT-IR spectra of pure and $\mathrm{CuSO}_{4}$ doped PVA/PVP polymer composite films are given in Figure 3.

\subsection{Ac Conductivity Measurement}

Ac conductance measurements for these films were made using Hioki LCR 3532 Hi-tester in the frequency range from $50 \mathrm{~Hz}$ to $5 \mathrm{MHz}$ at room temperature. Variation of conductivity calculated with log frequency is as shown in Figure 4. 

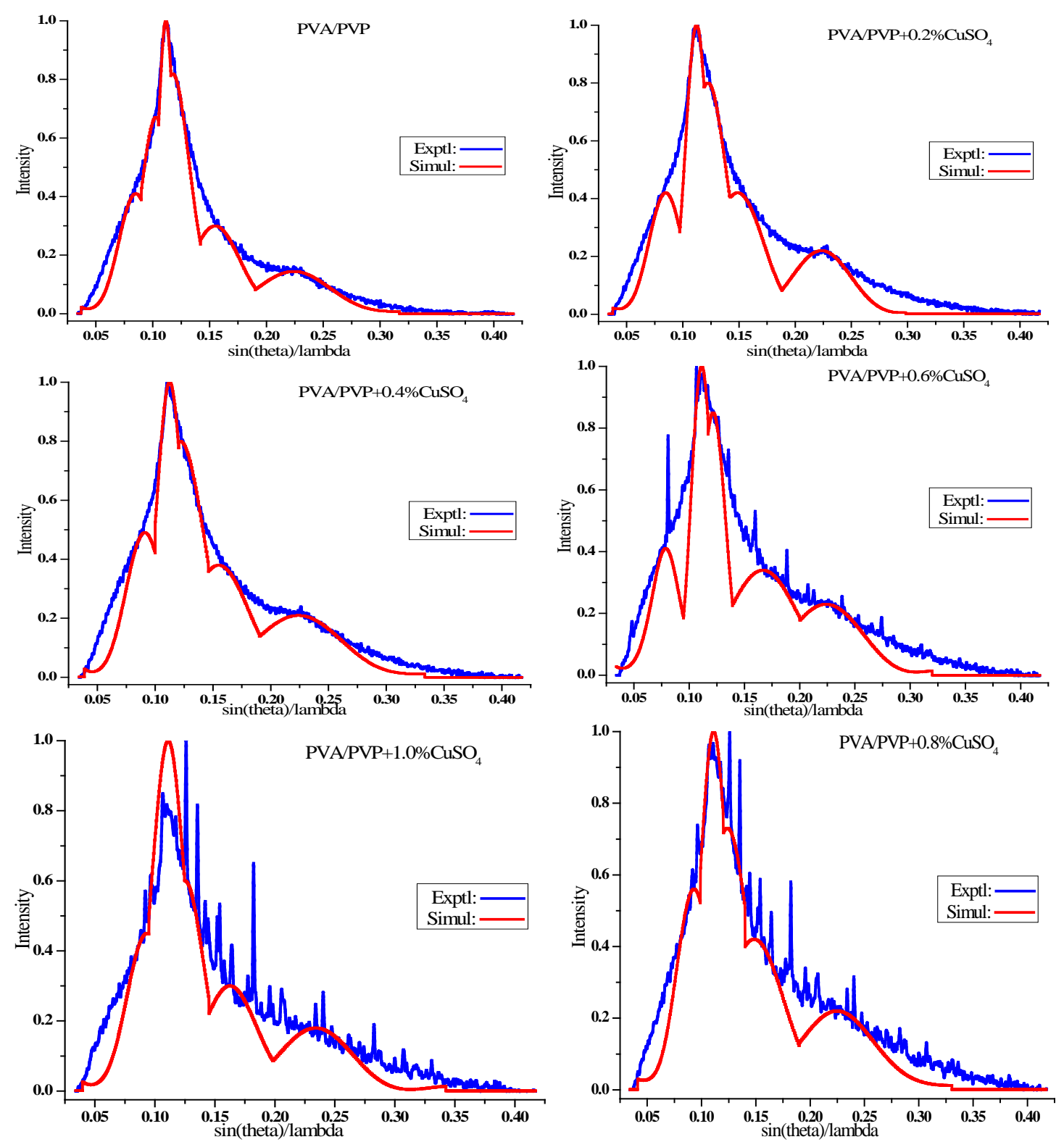

Figure 1. Experimental and simulated XRD pattern of pure and $\mathrm{CuSO}_{4}$ doped $\mathrm{PVA} / \mathrm{PVP}$ polymer composites.

\section{Result and Discussion}

\subsection{X-Ray Diffraction Studies}

Experimental and simulated XRD pattern of pure and $\mathrm{CuSO}_{4}$ doped PVA/PVP polymer composite films are shown in Figure 1. From Figure 1 a broad peak at $20^{\circ}$ and a less intense peak at $41^{\circ}$ observed for pure PVA/ PVP film shows semicrystalline nature of the film. As the concentration of the dopant increases the peaks becomes more broad and less intense which are due to the disruption of the PVA/PVP crystalline structure by the added $\mathrm{CuSO}_{4}$. Using this XRD data microstructural parameters were computed from line profile analysis [32]. The obtained data from the line profile analysis were further used in the refinement by whole powder pattern fitting method. These values are listed in Table 1. Figure 1 shows the goodness of the fit between the experimental and simulated XRD profile by whole powder pattern fitting method. From Table 1, it is seen that the average crystallite size varies with the concentration of dopant. Also the average lattice strain in these polymer composites are found to be vary between $0 \%$ and $1.5 \%$, further the broadness of the peak which is generally 


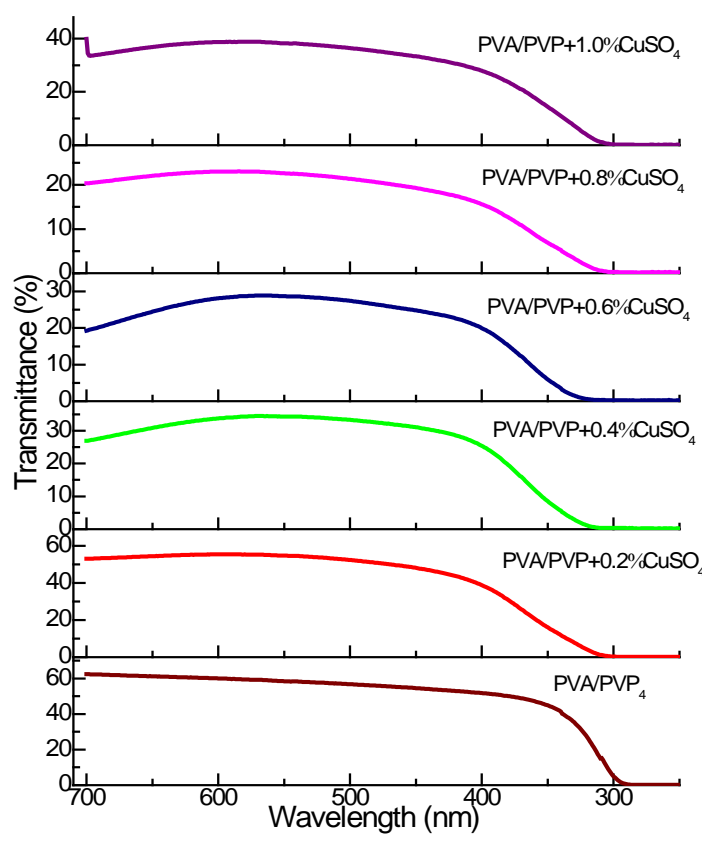

Figure 2. UV-Vis spectra of pure and $\mathrm{CuSO}_{4}$ doped PVA/PVP polymer composite films.

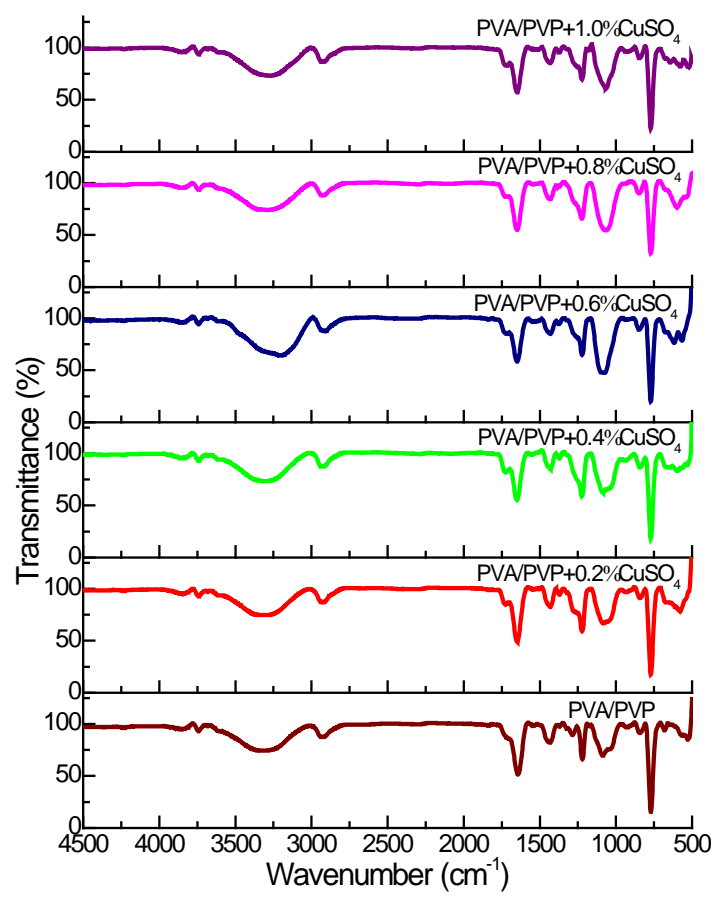

Figure 3. FT-IR spectra of pure and $\mathrm{CuSO}_{4}$ doped PVA/PVP polymer composite films.

the measure of FWHM is also given in Table 1.

The crystalline shape ellipsoids are obtained by plotting experimentally obtained size values and it is given in Figure 5. Area under these ellipsoids gives the crystalline area and it changes with the concentration of cupric sulphate. Maximum crystallite area was obtained for pure sample and minimum for $0.8 \%$ cupric sulphate in PVA/PVP. This is only a graphical illustration of shape ellipsoids with percentage. 


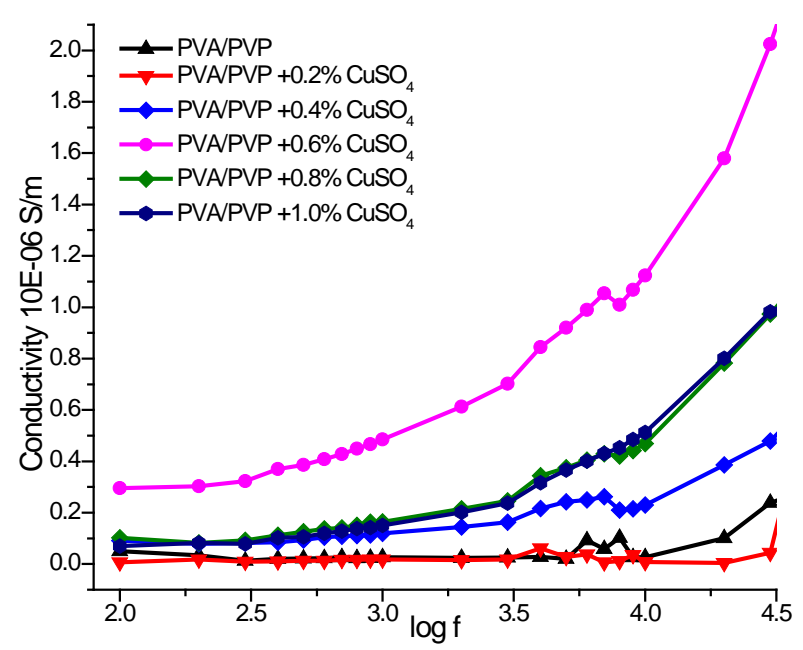

Figure 4. Variation of conductivity with log frequency.

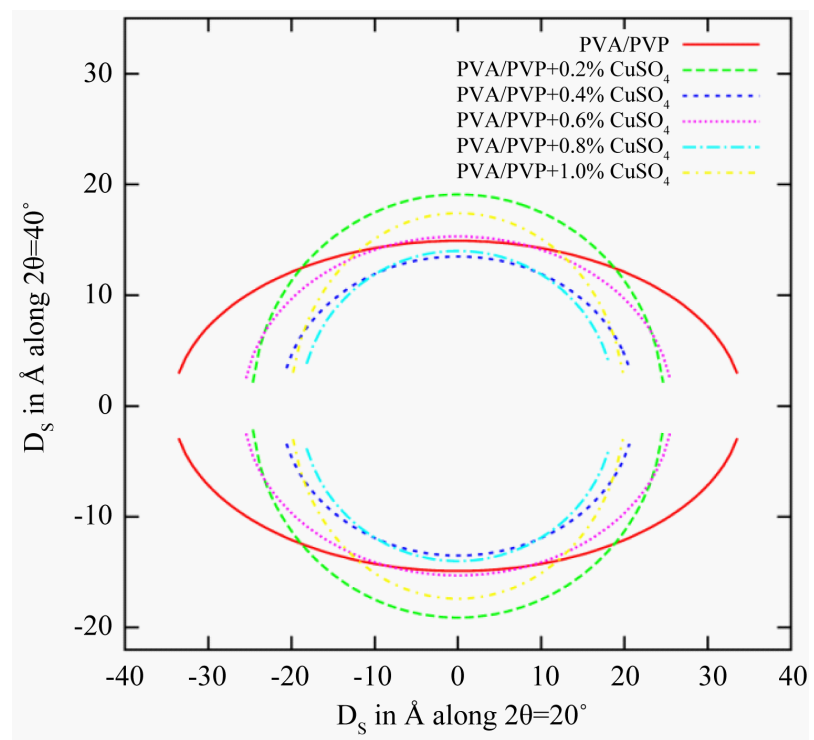

Figure 5. Variation of crystallite size of pure and $\mathrm{CuSO}_{4}$ doped polymer composite films.

\subsection{UV-Visible Spectroscopy Analysis}

A casual glance at Figure 2 indicates that PVA/PVP has high transmission and it decreases with the increase in concentration of $\mathrm{CuSO}_{4}$ in doped films. This is due to the formation of intermolecular hydrogen bonding between the ions of the dopant and the OH. The decrease in transmission for doped PVA/PVP films reflects the variation in the optical band gap which arises due to the change in polymer structure. We have made an attempt of evaluating optical band gap of these polymer composites using tauc plot. The derived tauc plot drawn against $(\alpha \mathrm{h} v)^{1 / 2}$ and $\mathrm{h} v$ is as shown in Figure 6. The calculated band gap values along with conductivity, electronic specific heat and statistical performance index are given in Table 2.

Since there are too many physical parameters have been experimentally determined, we have used multivariate analysis technique which is as follows. Each parameter that we have determined has been given a weightage. Then the sum of the weightage times the value of the physical parameters has been computed by normalising it with total sum of the weightage. This parameter has been identified as statistical performance index. In this work $35 \%$ weightage is given to crystallite size, $25 \%$ to each conductivity and energy gap and remaining $15 \%$ to electronic specific heat. From Table 2 it is found that the statistical performance index is high in the range 
Table 1. Microstructural parameters of the samples using exponential distribution function.

\begin{tabular}{|c|c|c|c|c|c|c|c|c|}
\hline Sample & $2 \theta\left(^{\circ}\right)$ & $\mathrm{d}(\AA)$ & $<N>$ & $\mathrm{D}(\AA)$ & g (\%) & $\alpha$ & FWHM & Delata E-03 \\
\hline \multirow{6}{*}{ PVA/PVP } & 15.10 & 5.86 & 2.21 & $12.9 \pm 0.6$ & 1.5 & $9.9 \pm 0.5$ & 6.9 & \multirow{6}{*}{0.70} \\
\hline & 18.30 & 4.84 & 2.68 & $15.7 \pm 0.8$ & 0.5 & $1.8 \pm 0.1$ & 6.6 & \\
\hline & 19.80 & 4.48 & 5.84 & $34.2 \pm 1.5$ & 0.0 & $1.1 \pm 0.1$ & 3.1 & \\
\hline & 20.85 & 4.26 & 2.64 & $15.5 \pm 0.7$ & 0.5 & $1.7 \pm 0.1$ & 7.6 & \\
\hline & 27.67 & 3.22 & 2.48 & $14.5 \pm 0.6$ & 0.5 & $2.0 \pm 0.1$ & 11.3 & \\
\hline & 40.46 & 2.23 & 2.54 & $14.9 \pm 0.7$ & 0.5 & $2.5 \pm 0.1$ & 17.3 & \\
\hline \multirow{6}{*}{$\begin{array}{l}\mathrm{PVA} / \mathrm{PVP}+ \\
0.2 \% \mathrm{CuSO}_{4}\end{array}$} & 15.04 & 5.88 & 2.22 & $13.0 \pm 0.6$ & 0.5 & $9.5 \pm 0.5$ & 6.9 & \multirow{6}{*}{1.08} \\
\hline & 19.93 & 4.45 & 4.24 & $24.8 \pm 1.3$ & 0.5 & $1.5 \pm 0.1$ & 4.4 & \\
\hline & 21.77 & 4.08 & 2.56 & $15.0 \pm 0.8$ & 0.5 & $1.7 \pm 0.1$ & 8.3 & \\
\hline & 26.56 & 3.36 & 2.47 & $14.5 \pm 0.7$ & 0.0 & $8.5 \pm 0.4$ & 10.8 & \\
\hline & 40.33 & 2.23 & 3.26 & $19.1 \pm 0.9$ & 0.5 & $2.4 \pm 0.2$ & 13.1 & \\
\hline & 16.16 & 5.48 & 2.19 & $12.8 \pm 0.6$ & 0.5 & $9.0 \pm 0.4$ & 7.5 & \\
\hline \multirow{6}{*}{$\begin{array}{l}\mathrm{PVA} / \mathrm{PVP}+ \\
0.4 \% \mathrm{CuSO}_{4}\end{array}$} & 20.00 & 4.43 & 3.64 & $21.3 \pm 1.0$ & 1.0 & $1.4 \pm 0.1$ & 5.2 & \multirow{6}{*}{0.85} \\
\hline & 21.64 & 4.10 & 2.27 & $13.3 \pm 0.7$ & 0.0 & $9.9 \pm 0.5$ & 9.6 & \\
\hline & 27.67 & 3.08 & 2.28 & $13.4 \pm 0.7$ & 0.5 & $8.2 \pm 0.4$ & 12.4 & \\
\hline & 40.46 & 2.25 & 2.31 & $13.5 \pm 0.7$ & 0.0 & $9.2 \pm 0.4$ & 19.3 & \\
\hline & 13.97 & 6.33 & 2.20 & $12.9 \pm 0.6$ & 0.0 & $9.1 \pm 0.4$ & 6.5 & \\
\hline & 19.77 & 4.49 & 4.41 & $25.8 \pm 1.3$ & 0.5 & $1.6 \pm 0.1$ & 4.2 & \\
\hline \multirow{6}{*}{$\begin{array}{l}\mathrm{PVA} / \mathrm{PVP}+ \\
0.6 \% \mathrm{CuSO}_{4}\end{array}$} & 21.62 & 4.10 & 4.01 & $23.5 \pm 1.2$ & 0.5 & $1.8 \pm 0.1$ & 5.1 & \multirow{6}{*}{1.56} \\
\hline & 29.84 & 2.99 & 2.14 & $12.5 \pm 0.6$ & 0.5 & $9.7 \pm 0.5$ & 15.2 & \\
\hline & 40.42 & 2.23 & 2.61 & $15.3 \pm 0.8$ & 0.0 & $7.0 \pm 0.4$ & 16.8 & \\
\hline & 16.52 & 5.36 & 2.25 & $13.2 \pm 0.7$ & 0.5 & $8.9 \pm 0.5$ & 7.4 & \\
\hline & 19.74 & 4.49 & 3.23 & $18.9 \pm 0.9$ & 0.5 & $1.9 \pm 0.1$ & 5.9 & \\
\hline & 22.03 & 4.03 & 2.43 & $14.2 \pm 0.7$ & 0.5 & $7.6 \pm 0.4$ & 8.9 & \\
\hline \multirow{6}{*}{$\begin{array}{l}\mathrm{PVA} / \mathrm{PVP}+ \\
0.8 \% \mathrm{CuSO}_{4}\end{array}$} & 26.49 & 3.36 & 2.17 & $12.7 \pm 0.6$ & 0.5 & $9.0 \pm 0.5$ & 13.1 & \multirow{6}{*}{1.16} \\
\hline & 40.58 & 2.22 & 2.39 & $14.0 \pm 0.7$ & 0.5 & $2.2 \pm 0.1$ & 18.8 & \\
\hline & 16.58 & 5.34 & 2.20 & $12.9 \pm 0.6$ & 0.5 & $9.2 \pm 0.5$ & 7.7 & \\
\hline & 19.74 & 4.49 & 3.43 & $20.1 \pm 1.0$ & 0.5 & $1.7 \pm 0.1$ & 5.5 & \\
\hline & 22.23 & 3.99 & 2.86 & $16.8 \pm 0.8$ & 0.5 & $2.1 \pm 0.1$ & 7.6 & \\
\hline & 29.05 & 3.07 & 2.57 & $15.1 \pm 0.7$ & 0.5 & $2.0 \pm 0.1$ & 11.5 & \\
\hline \multirow{6}{*}{$\begin{array}{l}\mathrm{PVA} / \mathrm{PVP}+ \\
1.0 \% \mathrm{CuSO}_{4}\end{array}$} & 42.36 & 2.13 & 2.97 & $17.4 \pm 0.8$ & 0.5 & $3.0 \pm 0.2$ & 19.8 & \multirow{6}{*}{1.37} \\
\hline & 15.10 & 5.86 & 2.21 & $12.9 \pm 0.6$ & 1.5 & $9.9 \pm 0.5$ & 6.9 & \\
\hline & 18.30 & 4.84 & 2.68 & $15.7 \pm 0.8$ & 0.5 & $1.8 \pm 0.1$ & 6.6 & \\
\hline & 19.80 & 4.48 & 5.84 & $34.2 \pm 1.5$ & 0.0 & $1.1 \pm 0.1$ & 3.1 & \\
\hline & 20.85 & 4.26 & 2.64 & $15.5 \pm 0.7$ & 0.5 & $1.7 \pm 0.1$ & 7.6 & \\
\hline & 27.67 & 3.22 & 2.48 & $14.5 \pm 0.6$ & 0.5 & $2.0 \pm 0.1$ & 11.3 & \\
\hline
\end{tabular}




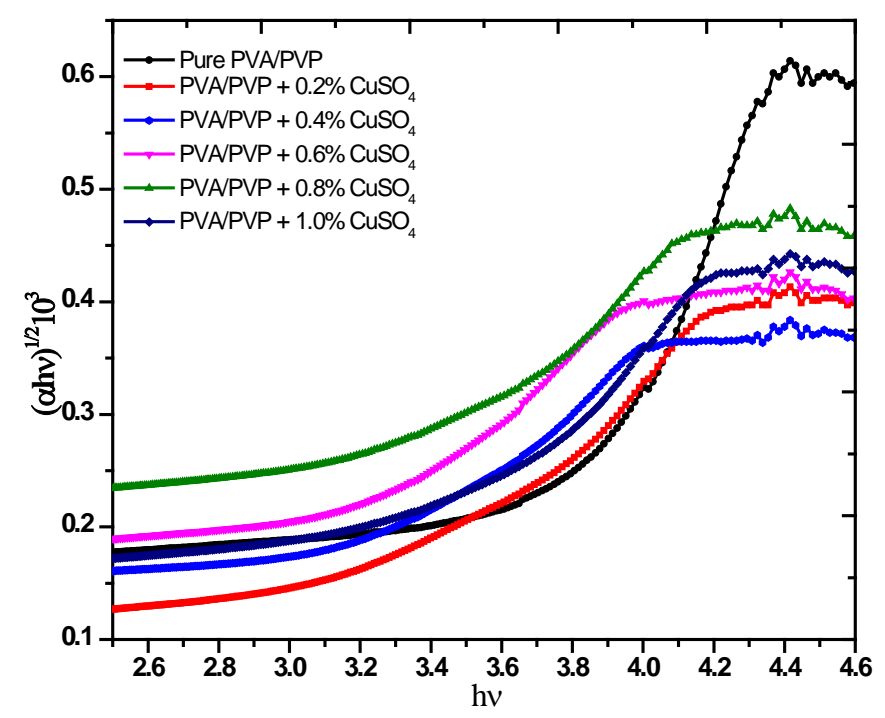

Figure 6. Tauc plot for pure and $\mathrm{CuSO}_{4}$ doped polymer composite polymer films.

Table 2. Optical band gap values with stastical performance index.

\begin{tabular}{cccccc}
\hline $\begin{array}{c}\text { Concentration } \\
(\%)\end{array}$ & $\begin{array}{c}\text { Crystallite size } \\
(\AA)\end{array}$ & $\begin{array}{c}\text { Conductivity at } 1 \mathrm{kHz} \\
\mathrm{E}-06(\mathrm{~S} / \mathrm{m})\end{array}$ & $\begin{array}{c}\text { Optical band gap } \\
(\mathrm{eV})\end{array}$ & $\begin{array}{c}\text { Electronic specific heat } \\
C_{v} \mathrm{E}-22(\mathrm{~J} / \mathrm{K})\end{array}$ & $\begin{array}{c}\text { Statistical performance } \\
\text { index }\end{array}$ \\
\hline 0 & 12.9 & 0.03 & 5.58 & 1.18 & 6.11 \\
0.2 & 24.8 & 0.17 & 3.53 & 1.12 & 9.79 \\
0.4 & 21.3 & 0.12 & 2.01 & 1.20 & 8.18 \\
0.6 & 25.8 & 0.48 & 1.40 & 0.97 & 9.66 \\
0.8 & 18.9 & 0.16 & 0.79 & 1.02 & 7.01 \\
1.0 & 20.1 & 0.15 & 2.92 & 0.94 & 7.94 \\
\hline
\end{tabular}

$0.2 \%$ to $0.6 \% \mathrm{CuSO}_{4}$ in PVA/PVA. In this range of concentration the values of crystallite size, conductivity, optical band gap and electronic specific heat which are determined experimentally are good.

\subsection{Fourier-Transformed Infrared (FT-IR) Spectroscopy Analysis}

The FT-IR spectra recorded in the wave number range $4000-500 \mathrm{~cm}^{-1}$ exhibit bands characteristic of stretching and bending vibrations of the films. FT-IR absorption bands positions and the assignments of all the prepared samples are listed in Table 3 . From Table 3 it is found that the bands corresponding $\mathrm{C}-\mathrm{H}$ stretching, $\mathrm{C}=\mathrm{O}$ stretching, $\mathrm{C}-\mathrm{O}$ stretching and $\mathrm{C}=\mathrm{O}$ bending shift towards higher wavenumber region while $\mathrm{O}-\mathrm{H}$ stretching towards lower waver number region. This clearly indicates that the stretching and bending vibrations are affected by the presence of copper ion.

\subsection{Ac Conductivity Measurements}

Prepared films of known thickness $d$ were placed between the electrodes of known area $A$ of LCR meter. The measured conductance $\sigma(\omega)$ from $50 \mathrm{~Hz}-5 \mathrm{MHz}$ was used to calculate conductivity $\sigma(\omega)$ using the following equation.

$$
\sigma(\omega)=\frac{G(\omega) \times d}{A}
$$


From Figure 4 it is observed that for $0.2 \%$ cupric sulphate doped PVA/PVP sample conductivity remains same as that of pure PVA/PVP sample. As the concentration dopant increases conductivity is also increases due to more ions available for conduction. For 1\% cupric sulphate doped PVA/PVP sample conductivity reaches to 2 $\mu \mathrm{S} / \mathrm{m}$ at higher frequency region. The calculated values of conductivity at frequency $1 \mathrm{kHz}$ for various concentrations of $\mathrm{CuSO}_{4}$ in PVA/PVP blendis also given in Table 2. From Table 2 it is found that with increase in concentration there is an increase in Ac conductivity, which is due to the doped free ions. In normal metals, the Ac conductivity becomes complex athigh frequencies. Here also there is an inherent DC conductivity contribution in these composites. A plot of conductivity and specific heat at $1 \mathrm{kHz}$ with respect to concentration has been given in Figure 7. This variation of conductivity shows an interesting behaviour which is independent of specific heat.

\section{Conclusion}

Following important results emerge from the present investigation. PVA/PVP doped with $\mathrm{CuSO}_{4}$ form physically and thermally stable uniform transparent films. X-ray investigations indicate the description of well organized polymer network. FT-IR study clearly indicates that the change in the observed absorption bands in the region 1000 to $1500 \mathrm{~cm}^{-1}$ is due to the presence of copper ions. UV-Vis spectra show the existence of optical energy gap in these films and it has maximum value corresponding to a concentration of $0.2 \% \mathrm{CuSO}_{4}$ in the samples. Conductivity studies also show a maximum corresponding to a particular concentration of $0.2 \% \mathrm{CuSO}_{4}$ in these blends. All these results indicate that the film is stable, photosensitive and reasonable improvement in conductivity.

\begin{tabular}{|c|c|c|c|c|c|}
\hline Sample & $\begin{array}{c}\mathrm{O}-\mathrm{H} \\
\text { stretching }\left(\mathrm{cm}^{-1}\right)\end{array}$ & $\begin{array}{c}\text { C-H } \\
\text { stretching }\left(\mathrm{cm}^{-1}\right)\end{array}$ & $\begin{array}{c}\mathrm{C}=\mathrm{O} \\
\text { stretching }\left(\mathrm{cm}^{-1}\right)\end{array}$ & $\begin{array}{c}\text { C-O } \\
\text { stretching }\left(\mathrm{cm}^{-1}\right)\end{array}$ & $\begin{array}{c}\mathrm{C}=\mathrm{O} \\
\text { bending }\left(\mathrm{cm}^{-1}\right)\end{array}$ \\
\hline PVA/PVP & 3319 & 2980 & 1624 & 1113 & 755 \\
\hline $\mathrm{PVA} / \mathrm{PVP}+0.2 \% \mathrm{CuSO}_{4}$ & 3317 & 2990 & 1628 & 1105 & 762 \\
\hline $\mathrm{PVA} / \mathrm{PVP}+0.4 \% \mathrm{CuSO}_{4}$ & 3311 & 2987 & 1629 & 1101 & 759 \\
\hline $\mathrm{PVA} / \mathrm{PVP}+0.6 \% \mathrm{CuSO}_{4}$ & 3311 & 2987 & 1629 & 1119 & 759 \\
\hline $\mathrm{PVA} / \mathrm{PVP}+0.8 \% \mathrm{CuSO}_{4}$ & 3311 & 2986 & 1629 & 1101 & 764 \\
\hline $\mathrm{PVA} / \mathrm{PVP}+1.0 \% \mathrm{CuSO}_{4}$ & 3311 & 2989 & 1629 & 1114 & 762 \\
\hline
\end{tabular}

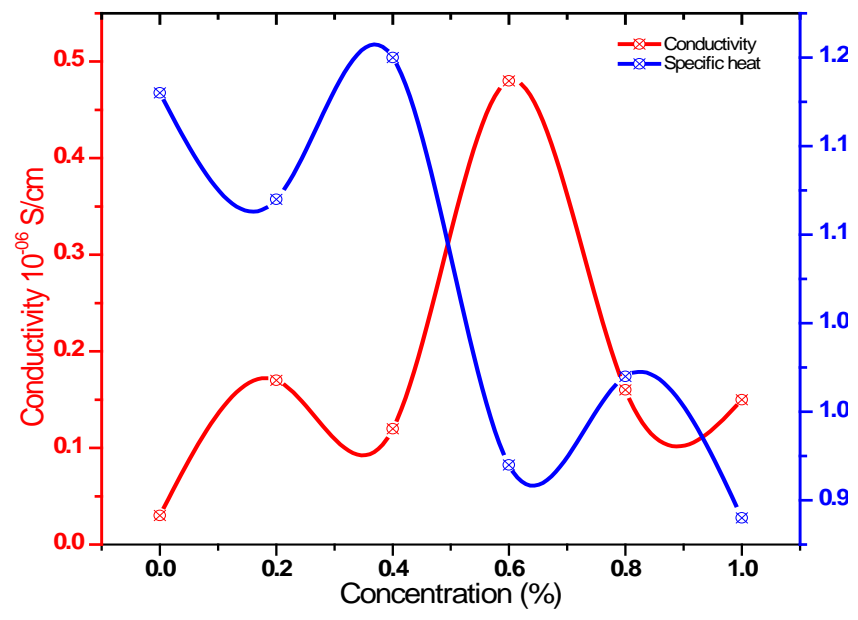

Figure 7. Variation of conductivity and electronic specific heat with concentration. 


\section{Acknowledgements}

Mrs. K.H.L thanks UGC for providing fellowship for this research under Faculty Improvement Program. Authors thank UGC, India for grants in the form of UPE/CPEPA projects. Thejas Urs G and Dr Mahadevaiah's suggestions in preparing the samples are acknowledged.

\section{References}

[1] Hadi, A.G., Lafta, F., Hashim, A., Hakim, H., Al-Zuheiry, A.I.O., Salman, S.R. and Ahmed, H. (2013) Study the Effect of Barium Sulphate on Optical Properties of Polyvinyl Alcohol (PVA). Universal Journal of Materials Science, 1, 52-55.

[2] Hassan, M.A., Gouda, M.E. and Sheha, E. (2010) Investigations on the Electrical and Structural Properties of PVA Doped with $\left(\mathrm{NH}_{4}\right)_{2} \mathrm{SO}_{4}$. Journal of Applied Polymer Science, 116, 1213-1217.

[3] De-Queiroz, A.A.A., Soares, D.A.W., Trzesniak, P., Gustavo, A. and Abraham (2001) Resistive-Type Humidity Sensors Based on PVP-Co and PVP-I I $_{2}$ Complexes. Journal of Polymer Science, 39, 459-469. http://dx.doi.org/10.1002/1099-0488(20010215)39:4<459::AID-POLB1019>3.0.CO;2-T

[4] Singh, R. and Kulkarni, S.G. (2013) Morphological and Mechanical Properties of Poly(Vinyl Alcohol) Doped with Inorganic Fillers. International Journal of Polymeric Materials and Polymeric Biomaterials, 62, 351-357. http://dx.doi.org/10.1080/00914037.2012.700288

[5] Gouda, M.E., Badr, S.K., Hassan, M.A. and Sheha, E. (2011) Impact of Ethylene Carbonate on Electrical Properties of $\mathrm{PVA} /\left(\mathrm{NH}_{4}\right)_{2} \mathrm{SO}_{4} / \mathrm{H}_{2} \mathrm{SO}_{4}$ Proton-Conductive Membrane. Ionics, 17, 255-261. http://dx.doi.org/10.1007/s11581-010-0506-2

[6] El-Khodary, A. (2010) Evolution of the Optical, Magnetic and Morphological Properties of PVA Films Filled with $\mathrm{CuSO}_{4}$. Physica-B, 405, 3401-3408. http://dx.doi.org/10.1016/j.physb.2010.05.012

[7] Sharaf, F., Mansour, S.A. and El-Lawindy, A.M.Y. (1999) Mechanical and Relaxation Properties of $\gamma$-Irradiated PVA Doped with Ferrous Sulphate. Polymer Degradation and Stability, 66, 173-177. http://dx.doi.org/10.1016/S0141-3910(98)00101-3

[8] Basha, A.F. and Basha, M.A.F. (2012) Structural and Thermal Degradation Studies on Thin Films of the Nanocomposite System PVP-Ce( $\left(\mathrm{SO}_{4}\right)_{2} \cdot 4 \mathrm{H}_{2} \mathrm{O}$. Polymer Bulletin, 68, 151-165. http://dx.doi.org/10.1007/s00289-011-0546-4

[9] Umaa, T., Mahalingam, T. and Stimming, U. (2004) Conductivity and Thermal Studies of Solid Polymer Electrolytes Prepared by Blending Polyvinylchloride, Polymethylmethacrylate and Lithium Sulfate. Materials Chemistry and Physics, 85, 131-136. http://dx.doi.org/10.1016/j.matchemphys.2003.12.012

[10] Kim, S.J., Park, S.J., Kim, I.Y., Lee, Y.H. and Kim, S.I. (2002) Thermal Characteristics of Poly(Vinyl Alcohol) and Poly(Vinylpyrrolidone) IPNs. Journal of Applied Polymer Science, 86, 1844-1847. http://dx.doi.org/10.1002/app.11096

[11] Yu, H., Xu, X., Chen, X., Lu, T., Zhang, P. and Jing, X. (2007) Preparation and Antibacterial Effects of PVA-PVP Hydrogels Containing Silver Nanoparticles. Journal of Applied Polymer Science, 103, 125-133. http://dx.doi.org/10.1002/app.24835

[12] Qiao, J., Fu, J., Lin, R., Mac, J. and Liu, J. (2010) Alkaline Solid Polymer Electrolyte Membranes Based on Structurally Modified PVA/PVP with Improved Alkali Stability. Polymer, 51, 4850-4859. http://dx.doi.org/10.1016/j.polymer.2010.08.018

[13] Hassan, M.A., Gouda, M.E. and Sheha, E. (2010) Investigations on the Electrical and Structural Properties of PVA Doped with $\left(\mathrm{NH}_{4}\right)_{2} \mathrm{SO}_{4}$. Journal of Applied Polymer Science, 116, 1213-1217.

[14] Mahmoud, K.H. and Atef, K. (2014) Optical and Colorimetric Studies of Thorium Nitrate-Doped Poly(vinyl alcohol) Films. Polymer Composites, 35, 1786-1791. http://dx.doi.org/10.1002/pc.22832

[15] Bhajantri, R.F., Ravindrachary, V., Poojary, B., Ismayil, Harisha, A. and Crasta, V. (2009) Studies on Fluorescent PVA + PVP + MPDMAPP Composite Films. Polymer Engineering and Science, 49, 903-909. http://dx.doi.org/10.1002/pen.21341

[16] Basha, M.A.F. (2010) Magnetic and Optical Studies on Polyvinylpyrrolidone Thin Films Doped with Rare Earth Metal Salts. Polymer Journal, 42, 728-734. http://dx.doi.org/10.1038/pj.2010.60

[17] Abou-Taleb, M.H. (2009) Thermal and Spectroscopic Studies of Poly(N-vinyl pyrrolidone)/Poly(vinyl alcohol) Blend Films. Journal of Applied Polymer Science, 114, 1202-1207. http://dx.doi.org/10.1002/app.30082

[18] Abdelrazek, E.M., Elashmawi, I.S. and Labeeb, S. (2010) Chitosan Filler Effects on the Experimental Characterization, Spectroscopic Investigation and Thermal Studies of PVA/PVP Blend Films. Physica B, 405, 2021-2027. http://dx.doi.org/10.1016/j.physb.2010.01.095 
[19] Ragab, H.M. (2011) Spectroscopic Investigations and Electrical Properties of PVA/PVP Blend Filled with Different Concentrations of Nickel Chloride. Physica B, 406, 3759-3767. http://dx.doi.org/10.1016/j.physb.2010.11.030

[20] Sedlarik, V, Saha, N., Kuritka, I. and Saha, P. (2006) Characterization of Polymeric Biocomposite Based on Poly(vinyl alcohol) and Poly(vinyl pyrrolidone). Polymer Composites, 27, 147-152. http://dx.doi.org/10.1002/pc.20197

[21] Scardi, P. and Leoni, M. (2002) Whole Powder Pattern Modelling. Acta Crystallographica Section A, 58, $190-200$. http://dx.doi.org/10.1107/S0108767301021298

[22] Somashekar, R., Hall, I.H. and Carr, P.D. (1989) The Determination of Crystal Size and Disorder from X-Ray Diffraction Photographs of Polymer Fibres. 1. The Accuracy of Determination of Fourier Coefficients of the Intensity Profile of a Reflection. Journal of Applied Crystallography, 22, 363-371. http://dx.doi.org/10.1107/S0021889889004085

[23] Warren, B.E. and Averbach, B.L. (1950) The Effect of Cold-Work Distortion on X-Ray Patterns. Journal of Applied Physics, 21, 595-599. http://dx.doi.org/10.1063/1.1699713

[24] Hall, I.H. and Somashekar, R. (1991) The Determination of Crystal Size and Disorder from the X-Ray Diffraction Photograph of Polymer Fibres. 2. Modelling Intensity Profiles. Journal of Applied Crystallography, 24, 1051-1059. http://dx.doi.org/10.1107/S0021889891007707

[25] Shahmoradi, B., Ibrahim, I.A., Sakamoto, N., Ananda, S., Somashekar, R., Row, T.N.G. and Byrappa, K. (2010) Photocatalytic Treatment of Municipal Wastewater Using Modified Neodymium Doped $\mathrm{Tio}_{2}$ Hybrid Nanoparticles. Journal of Environmental Science and Health Part A, 45, 1248-1255. http://dx.doi.org/10.1080/10934529.2010.493807

[26] Stokes, A.R. (1948) A Numerical Fourier-Analysis Method for the Correction of Widths and Shapes of Lines on XRay Powder Photographs. Proceedings of Physical Society London, 61, 382-391. http://dx.doi.org/10.1088/0959-5309/61/4/311

[27] Warren, B.E. (1969) X-Ray Diffraction. Addison-Wesley, New York.

[28] Press, W.H., Teukolsky, S.A., Vetterling, W.T. and Flannery, B.P. (1996) Numerical Recipes in Fortran 90: The Art of Parallel Scientific Computing. 2nd Edition, Cambridge University Press, Cambridge.

[29] Parameswara, P., Demappa, T., Mahadevaiah, Prakash, Y., Somashekarappa, H., Byrappa, K. and Somashekar, R. (2012) Polymeric Degradation of Water Soluble Chitosan/HPMC Films Using WAXS Data. Material Research Innovations, 16, 126-129. http://dx.doi.org/10.1179/1433075X11Y.0000000028

[30] Mallu, P., Siddaramaiah and Somashekar, R. (2000) Synthesis and Characterization of Castor Oil Based PolyurethanePolyacrylonitrile Interpenetrating Polymer Networks. Bulletin of Material Sciences, 23, 413-418. http://dx.doi.org/10.1007/BF02708392

[31] Divakara, S., Madhu, S. and Somashekar, R. (2009) Stacking Faults and Microstructural Parameters in Non-Mulberry Silk Fibres. Pramana, 73, 927-938. http://dx.doi.org/10.1007/s12043-009-0159-8

[32] Prakash, Y., Mahadevaiah, Somashekarappa, H., Demappa, T. and Somashekar, R. (2012) Microstructural Parameters of HPMC/PVP Polymer Blends Using Wide Angle X-Ray Technique. Journal of Research Updates in Polymer Science, 1, 24-31. http://dx.doi.org/10.6000/1929-5995.2012.01.01.4 